\title{
Did Bartonella henselae contribute to the deaths of two veterinarians?
}

\author{
Edward B. Breitschwerdt ${ }^{1,2}$
}

\begin{abstract}
Bartonella henselae, a flea-transmitted bacterium, causes chronic, zoonotic, blood stream infections in immunocompetent and immunocompromised patients throughout the world. As an intra-erythrocytic and endotheliotropic bacterium, B. henselae causes a spectrum of symptomatology ranging from asymptomatic bacteremia to fever, endocarditis and death. Veterinary workers are at occupational risk for acquiring bartonellosis. As an emerging, and incompletely understood, stealth bacterial pathogen, $B$. henselae may or may not have been responsible for the deaths of two veterinarians; however, recent evidence indicates that this genus is of much greater medical importance than is currently appreciated by the majority of the biomedical community.
\end{abstract}

Keywords: Infection, Disease, Mortality, Cancer, Heart valve, Blood

The question "Did Bartonella henselae contribute to the deaths of two veterinarians?" will never be definitively answered; however, after months of asking myself this question, I decided to comment on the possibility that a recently discovered stealth bacteria [1] may have played a role in their deaths. If one were to organize a physician/scientist review of each patient's medical record, examining the voluminous doctors', nurses', consultants' notes and hundreds of laboratory results; if this team were to visit with wives, family, and friends left behind, and had access to the test results generated by our research group (see acknowledgements) prior to and after their respective deaths, I am of the opinion that this question could never be accurately or adequately answered.

Perhaps questions for which there are not definitive answers should never be asked, but if true, there would be no need for biomedical research. Unfortunately, many questions remain unanswered, a fact that is very hard for patients, family members, doctors, and diagnosticians to accept. Medicine remains "a practice," based upon the best available science, the art of patient care, and a clinician's attempts to manage symptoms and disease processes for which causation is elusive. Because of circumstances

\footnotetext{
Correspondence: ed_breitschwerdt@ncsu.edu

${ }^{1}$ Intracellular Pathogens Research Laboratory and the Center for Comparative Medicine and Translational Research, College of Veterinary Medicine, North Carolina State University, Raleigh, NC, USA

${ }^{2}$ College of Veterinary Medicine, North Carolina State University, 1060 William Moore Dr., Raleigh, NC 27607, USA
}

\section{Ciomed Central}

(C) 2015 Breitschwerdt; licensee BioMed Central. This is an Open Access article distributed under the terms of the Creative Commons Attribution License (http://creativecommons.org/licenses/by/4.0), which permits unrestricted use, distribution, and reproduction in any medium, provided the original work is properly credited. The Creative Commons Public Domain Dedication waiver (http://creativecommons.org/publicdomain/zero/1.0/) applies to the data made available in this article unless otherwise stated. beyond everyone's control, involvement of my research laboratory team was less than optimal due to the timing of specimen collection and type of samples available for Bartonella testing.

Voltaire, (1694 to 1778), stated: "Doctors put drugs of which they know little, into our bodies of which they know less, to treat diseases of which they know nothing at all." Clearly, medical science and $21^{\text {st }}$ century patient care have advanced tremendously since Voltaire's time; however, there are still major gaps in scientific knowledge that negatively impact patient outcomes. Specifically, our collective lack of "knowledge" negatively impacts directed therapy and effective management of the patient's illness and deficiencies in medical knowledge related to the genus Bartonella continue to compromise patient care throughout the world.

It is my hope that this commentary will benefit future patients, particularly veterinary workers, who have been or will become infected with the emerging and incompletely understood, stealth bacterial pathogen; Bartonella henselae. The term "emerging infectious disease" has been abused and to an extent overused in recent years, often in association with efforts to influence the appropriation of research funding. During the past two decades, bartonellosis has clearly earned the designation "an emerging infectious disease." The genus Bartonella has expanded from two known species prior to 1992 to at least 34 Bartonella species in 2015. Medically, fifteen Bartonella species have

uns 
been associated with a spectrum of human illnesses; therefore, incompletely understood is another way to accurately describe this genus. The fascinating history of Bartonella has been summarized in recent reviews [2-4]; whereas the contemporary history of this genus is being written and rewritten as new knowledge is generated around the world. The past and more recent history of bartonellosis [1-4] is beyond the scope of this commentary. However, a brief historical perspective is necessary to put the lives and deaths of these veterinarians into context. Prior to the recognition that bacillary angiomatosis and peliosis hepatis were caused by Bartonella quintana or B. henselae in AIDS patients [5, 6], bartonellosis was not a differential diagnosis for sick humans or other animals throughout most of the world $[1,3]$. Prior to the AIDS epidemic, indigenous infection with a Bartonella sp. had never been diagnosed by a physician or veterinarian in North America. Not surprisingly, clinicians cannot diagnose an as yet "unknown or undiscovered" infectious agent. Importantly, the history of Bartonella spp. infections substantially pre-dates AIDS. Bartonella bacilliformis, transmitted by sandflies, caused Oroya Fever and verruga peruana in indigenous Peruvian Indians hundreds of years ago; infected Spanish conquistadors, and caused highly fatal illness in immigrant workers building the Trans Peruvian railroad [2-4]. Purportedly, one worker died of hemolytic anemia (Oroya Fever) for each railroad tie that was laid. A second Bartonella species, $B$. quintana, transmitted by the human body louse, was a major cause of morbidity and mortality during the World Wars [2-4], and continues to cause human suffering and death among a spectrum of people (urban trench fever), particularly individuals experiencing human body louse exposure in association with wars and famine, or those living in poverty and abusing drugs in modern day cities. Since the "rediscovery" of Bartonella species infections in AIDS patients, numerous new species have been implicated as a cause of illnesses in immunocompromised and immunocompetent patients $[2,7,8]$. Despite a dramatic expansion of medical and microbiological knowledge related to the genus Bartonella $[1,3,6]$, there are still major knowledge gaps involving clinically relevant questions.

\section{Findings}

Due to their lengthy illnesses, frequent medical evaluations, and involvement of numerous medical specialists and medical centers throughout the United States, only a brief, superficial overview of each veterinarian's illness is possible. As an example of the medical complexity, veterinarian \#1 was transferred among six different hospitals during the last 5 months of his life (October 2012 through February 2012). Selected historical and demographic information is summarized (Table 1). When I entered the University of Georgia, College of Veterinary
Medicine in 1970, Veterinarian \#1 was a professor. I will always remember him as a caring, enthusiastic, outgoing and intelligent teacher. Before I graduated, he left the University and started a companion animal veterinary practice, where he worked for the remainder of his career. On April 11th, 2011, I received this email communication from him: "Ed. 15 years ago, my cardiologist told me I was in an "elite group" of individuals as pertaining to cardiovascular fitness. Last week, we discovered I need a mitral, aortic and tricuspid valve replacement to be done this Friday. Remembering some of your articles, I believe you stated that the number 1 cause of culturenegative endocarditis in humans was bartonellosis. I have been hospitalized twice in the last 2 years for severe pneumonia. Do you think that is something I should check on and if so, what samples could I send to you to attempt culture or PCR. I hate to impose on you like this, but my cardiologist does not give it much weight nor does my family practitioner. Hope all is well with you and family."

Although our paths had crossed occasionally during the ensuing 38 years, this email request initiated his entry into our Institutional Review Board approved research study (North Carolina State University, 164-0805). This man was in good health until June 2010, when he lost consciousness, fell and was diagnosed with pneumonia. In April 2011, he had mitral valve replacement surgery, closure of a patent foramen ovale, 2-vessel bypass, bilateral maze procedure, radio frequency ablation, ligation of the left atrial appendage and pacemaker placement. Based upon self-reporting in a standardized questionnaire completed by all participants in our IRBapproved study, progressive symptoms including fatigue, disorientation, blurred vision, balance problems, difficulty remembering, eye pain, insomnia, muscle weakness, loss of sensation or numbness in the legs, and shortness of breath developed postoperatively in 2011. These non-specific symptoms are often reported by veterinary workers infected with one or co-infected with more than one Bartonella sp. [9-14]. Veterinarians, veterinary technicians, animal handlers, and groomers appear to be occupationally at risk groups for Bartonella spp. infections $[9,10]$. Because of their frequent exposure to arthropod-infested, Bartonella spp. bacteremic animals, we have suggested that veterinary workers represent a sentinel, research study population for clarifying the medical importance of the genus Bartonella [15, 16]. From the context of research priorities and research funding, this suggestion has been ignored by policy makers and governmental agencies in the United States.

Relapsing fever of unknown origin (FUO) with temperatures as high as $104{ }^{\circ} \mathrm{F}$, developed in October 2011 (6 months after surgery). Despite various antibiotic therapies, febrile episodes, accompanied by periodic dizziness 
Table 1 Historical and demographic findings extracted from the study questionnaire provided by the two veterinarians infected with Bartonella henselae

\begin{tabular}{|c|c|c|}
\hline Parameter & Veterinarian \#1 & Veterinarian \#2 \\
\hline Age & 67 & 63 \\
\hline Sex & Male & Male \\
\hline Ethnicity & Caucasian & Caucasian \\
\hline Residence & Suburban & Suburban \\
\hline Number of children & Daughter & 2 Sons \\
\hline Employment Status & Full-time employed & Full-time employed \\
\hline Occupation & Veterinarian & Veterinarian \\
\hline Length of time at current position & 44 years & 37 years \\
\hline Medical coverage & Yes & Yes \\
\hline Have you been diagnosed with infectious disease & Yes- pneumonia & Yes - childhood diseases, influenza \\
\hline Have you been diagnosed with a chronic illness & Yes- approximately 2 years duration & Yes - mild colitis, gastric reflux \\
\hline Allergies & Yes - Environmental & Yes - mild seasonal rhinitis \\
\hline Has experienced persistent illness & Yes & No \\
\hline Self-described health & Infrequently ill & Healthy \\
\hline \multicolumn{3}{|l|}{ History of symptoms: } \\
\hline Fatigue & Yes & No \\
\hline Difficulty remembering & Yes & No \\
\hline Disoriented (confused by time or place) & Yes & No \\
\hline Eye Pain & Yes & No \\
\hline Difficulty sleeping (insomnia) & Yes & No \\
\hline Chronic fatigue & Yes & No \\
\hline Bladder dysfunction & Yes & No \\
\hline Fever & Yes & No \\
\hline Mental confusion (disordered thoughts) & Yes & No \\
\hline Blurred vision & Yes & No \\
\hline Balance problems & Yes & No \\
\hline Shortness of breath & Yes & No \\
\hline Muscle weakness & Loss of sensation or numbness in legs & $\begin{array}{l}\text { Legs - weak left lower leg since ICE chemotherapy - } \\
\text { symptoms almost gone }\end{array}$ \\
\hline $\begin{array}{l}\text { Ability to perform the same activities of daily } \\
\text { living prior to illness? }\end{array}$ & No & Yes, until medical leave began July 2012 \\
\hline $\begin{array}{l}\text { Ability to perform same employment/school } \\
\text { activities prior to illness? }\end{array}$ & No & Yes, until medical leave began July 2012 \\
\hline Self-reported signs of symptoms & Waxing/waning & Improving - with current cancer treatment \\
\hline \multicolumn{3}{|l|}{ History of Physician evaluations: } \\
\hline General Practitioner & Yes & Yes \\
\hline Pulmonologist & Yes & No \\
\hline Orthopedist & Yes & Yes \\
\hline Urologist & Yes & No \\
\hline Internal Medicine & Yes & Yes \\
\hline Infectious Disease & Yes & Yes \\
\hline Gastroenterologist & Yes & Yes \\
\hline Chiropractor & Yes & Yes \\
\hline Ophthalmologist & Yes & Yes \\
\hline
\end{tabular}


Table 1 Historical and demographic findings extracted from the study questionnaire provided by the two veterinarians infected with Bartonella henselae (Continued)

\begin{tabular}{lll}
\hline Dermatologist & Yes & Yes \\
Dentist & Yes & Yes \\
Cardiologist & Yes & Yes \\
Neurologist & Yes & No \\
Psychiatrist/Psychologist & Yes & No \\
Physical Therapist & Yes & No \\
Podiatrist & Yes & No \\
Allergist & Yes & Yes \\
Acupuncturist & No & Yes \\
Ear/Nose/Throat & No & Yes \\
Oncologist & No & Yes
\end{tabular}

\section{Family Medical History}

Heart Disease
Cancer
Hypertension
Asthma
Stroke
Substance Abuse
Allergies
Diabetes

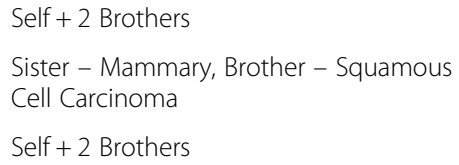

\section{Animal contact:}

Dog

Cat

Bird

Horse

Rodent

Reptile

Fish

Ferret

Age of Exposure

Allow pets to sleep in same bed as owner

Allow pets to lick hands, face, feet, etc.

Frequent exposure ( $>1$ time per month) to other animals

Length of exposure to other animals

Exposure to production animals

\section{Animal bites or scratches}

Dog

Cat

Bird

Horse

Reptile

Rabbit

Rodent
Yes
Yes
Yes
No
No
No
No
Yes
Yes
Yes
Yes

Father

Mother - Colon Cancer

Father + Mother

Mother

Self

Father

Yes - Indoor/Outdoor
Yes - Indoor/Outdoor
Yes - Indoor
Yes - Outdoor
Yes, Hampster - Indoor
Yes - Indoor
Yes
Yes
0-60+
Yes - cats only
Yes
Yes - Dog, Cats for 29 years.

No

First 8 years post-graduation, treated farm animals

No

Yes - since 1975

Yes - 1980

Yes - 1975

Yes - 1980

Yes - 1975

Yes - 1980 
Table 1 Historical and demographic findings extracted from the study questionnaire provided by the two veterinarians infected with Bartonella henselae (Continued)

Outdoor exposure at least once a year

Wildlife rescue/rehabilitation, Gardening Hiking, Hunting, Gardening, Cycling, Outdoor water sports

Antibiotics last 12 months:

Ciprofloxacin
Doxycycline
cefixime
Fluoroquinolones
Cephalosporins
Corticosteroids in past 12 months:
Medrol Pak
Flonase
Oral Prednisone
IV Prednisone
IV Dexamethasone

$\begin{array}{ll}\text { Current } & \text { No } \\ \text { Current } & \begin{array}{l}\text { Current *Rigors \& fevers stopped with start of } \\ \text { Doxycycline }\end{array} \\ \text { June-2011 } & \text { No } \\ \text { Yes } & \text { Yes } \\ \text { No } & \text { Yes } \\ \text { Yes } & \text { Yes } \\ 12 / 11 / 2011-12 / 26 / 2011 & \text { No } \\ 6 / 2011-\text { current } & \text { No } \\ \text { No } & \text { Yes } \\ \text { No } & \text { Yes } \\ \text { No } & \text { Yes }\end{array}$

Other medications in past 12 months

Quinapril

2000-current No

Qmlodipine

2000-current No

Escitalopram

1980-current $\quad$ No

Primidone

2007-current No

Coumadin

2011-current No

Aspirin $81 \mathrm{mg}$

1990-current No

Modafinil

2010-current No

Enalipril

No

Rosuvastatin calcium

No

Oral Antiviral

Oral Antifungal

No

No

No

No

No

No

No

No
Yes

Yes

Yes

Yes

Yes

Insect Exposure:

Fleas

Yes

Yes

Ticks

Yes

Yes

Biting Flies

Yes

Yes

Mosquitoes

Yes

Yes

Spiders

Yes

Yes

Scabies

Yes

Yes

Travel outside of state of residence

Northwest US

Yes

Yes

Northeast US

Yes

Yes

Southwest US

Yes

Yes

Southeast US

Yes

Yes

Animal Contact during Travel Within US

Northwest US

Yes

No

Northeast US

Yes

No

Southwest US

Yes

Yes

Southeast US

Yes

No 
Table 1 Historical and demographic findings extracted from the study questionnaire provided by the two veterinarians infected with Bartonella henselae (Continued)

\begin{tabular}{lll}
\hline Non continental US \& International Travel & & \\
Alaska & Yes & Yes \\
Mexico & Yes & Yes \\
Central America & Yes & Yes \\
Carribean & Yes & Yes \\
Canada & Yes & Yes \\
Australia/New Zealand/Fiji & No & Yes \\
Europe & No & Yes \\
Animal Contact during Travel Outside Non & & \\
continental US & & No \\
Alaska & Yes & No \\
Mexico & No & No \\
Central America & Yes & No \\
Carribean & Yes & No \\
Canada & No & No \\
Pet Travel & No & \\
Specialist Doctor Visits: & & Yes \\
Chronic mild colitis & No & Yes \\
T Cell Lymphoma & No & Duration 15 years - under control with statin \\
Hyperlipidemia & No & \\
\hline
\end{tabular}

and increasingly severe muscle weakness, continued until his death on February 24, 2013. Bartonella spp. are a cause of FUO and culture-negative endocarditis [17-20]. As reviewed by Chomel, et al. [17], the first description of human Bartonella endocarditis was published in 1993. Subsequently, Bartonella endocarditis was reported in cats, cows, dogs and sea otters [17].

Microbiological improvements in Bartonella sp. isolation methods and PCR amplification of organism-specific DNA sequences from surgically removed or autopsy obtained heart valves have resulted in the identification of Bartonella endocarditis cases throughout the world [17, 18 . Between January $23^{\text {rd }}$ and January $30^{\text {th }}, 2012$, multiple blood cultures were obtained after consultation with an infectious diseases physician, of which a subset was sent to our laboratory for Bartonella testing. FUO had persisted despite prior treatment with cefixime and concurrent administration of doxycycline and ciprofloxacin. When Mycobacterium interjectum grew in one blood culture processed by a commercial laboratory, the patient was treated with doxycycline and clarithromycin beginning in March 2012, followed by clofazimine and clarithromycin. Mycobacterium interjectum, a slow growing mycobacteria most often associated with immunosuppression, generally responds to antibiotic treatment. Bartonella henselae (SA2 genotype) was amplified and sequenced from one of three blood specimens submitted to our laboratory (Table 2). In September 2012, the patient's fever pattern worsened with temperatures spiking to $105^{\circ} \mathrm{F}, 2-3$ times/week. Due to the poor response to antibiotics, an extensive workup was performed. Bone marrow and liver biopsies contained granulomatous inflammation, which occurs in association with Bartonella, Mycobacterium and other intracellular pathogens. Bronchoscopic lavage culture grew $M$. interjectum and Eikenella corrodens, after which treatment consisted of tigecycline and prednisolone (60 mg daily), which he had been taking for most of the previous year for potential sarcoidosis. In January 2013, the patient was admitted to National Jewish Health, for evaluation of severe muscular weakness, dyspnea on exertion, memory loss and fever of unknown origin. During the diagnostic evaluations the patient's condition deteriorated resulting in transfer to the University of Colorado in Denver. After flying home to Florida, the patient was hospitalized at Bayfront Medical Center, after which he was transferred to Shands Hospital, University of Florida. On February $13^{\text {th }}, 2013$, after 13 hours of surgery for vegetative valvular endocarditis, valve replacement surgery, splenectomy, and pacemaker removal the patient never regained consciousness. The death certificate listed multi-organ failure, sepsis, and mycobacterial endocarditis as the cause of death. Nearly two years after his death, $B$. henselae with sequence identity of 527/527 bp with B. henselae Fizz, (Gen Bank accession number AF369526) was amplified and sequenced from a paraffin-embedded bone marrow specimen obtained in January 2012. The same B. henselae Fizz genotype 
Table 2 Bartonella spp. serology and PCR results from blood, serum, BAPGM enrichment blood culture and subculture agar plate swab or tissues from each of the two veterinarians

\begin{tabular}{|c|c|c|c|c|c|c|c|c|c|c|c|}
\hline \multirow[b]{2}{*}{ Veterinarian } & \multirow[b]{2}{*}{$\begin{array}{l}\text { Collection } \\
\text { Date }\end{array}$} & \multirow[b]{2}{*}{ Sample } & \multirow[b]{2}{*}{$\begin{array}{l}\text { PCR original } \\
\text { sample }\end{array}$} & \multirow[b]{2}{*}{$\begin{array}{l}\text { PCR } \\
\text { culture }\end{array}$} & \multirow[b]{2}{*}{$\begin{array}{l}\text { Subculture } \\
\text { isolate }\end{array}$} & \multicolumn{6}{|c|}{ Bartonella IFA reciprocal titers } \\
\hline & & & & & & $B \vee b \mid$ & $B \vee b \|$ & $B v b \| I$ & $\mathrm{BhHI}$ & BhSA2 & $B k$ \\
\hline \multirow[t]{14}{*}{$\# 1$} & $1 / 9 / 2012$ & FFPE Bone Marrow & Bh Fizz & N/A & $\mathrm{N} / \mathrm{A}$ & & & & & & \\
\hline & $1 / 23 / 2012$ & Serum & Neg & & & $<16$ & $<16$ & $<16$ & $<16$ & $<16$ & $<16$ \\
\hline & & Blood & Neg & Neg 7, 14 & Neg & & & & & & \\
\hline & $1 / 28 / 2012$ & Serum & Bh SA2 & & & & & & & & \\
\hline & & Blood & Neg & Neg 7, 14 & Neg & & & & & & \\
\hline & $1 / 30 / 2012$ & Serum & Neg & & & & & & & & \\
\hline & & Blood & Neg & $\operatorname{Neg} 7,14$ & Neg & & & & & & \\
\hline & $4 / 11 / 2012$ & Serum & Neg & & & $<16$ & $<16$ & $<16$ & $<16$ & $<16$ & $<16$ \\
\hline & & Blood & Neg & Neg 14 & Neg & & & & & & \\
\hline & $4 / 13 / 2012$ & Serum & Neg & & & & & & & & \\
\hline & & Blood & Neg & Neg 14 & Neg & & & & & & \\
\hline & $4 / 16 / 2012$ & Serum & Neg & & & & & & & & \\
\hline & & Blood & Neg & Neg 14 & & & & & & & \\
\hline & 2/13/2013 & $\begin{array}{l}\text { FFPE Mitral Valve } \\
\text { Prosthesis }\end{array}$ & Bh Fizz & N/A & N/A & & & & & & \\
\hline \multirow[t]{11}{*}{$\# 2$} & $2 / 24 / 2011$ & FFPE (LN supraclavicular) & Neg & N/A & N/A & & & & & & \\
\hline & $7 / 25 / 2012$ & FFPE (cervical LN) & Bh SA2 & $\mathrm{N} / \mathrm{A}$ & N/A & & & & & & \\
\hline & $4 / 5 / 2013$ & Serum & Neg & N/A & N/A & & & & & & \\
\hline & & Blood & Neg & Neg 7, 14 & Neg & $<16$ & $<16$ & $<16$ & $<16$ & $<16$ & $<16$ \\
\hline & $4 / 6 / 2013$ & Serum & Neg & & & & & & & & \\
\hline & & Blood & Neg & Neg 7, 14 & Neg & & & & & & \\
\hline & $4 / 6 / 2013$ & Serum & Neg & & & & & & & & \\
\hline & & Blood & Neg & Neg 7, 14 & Neg & & & & & & \\
\hline & $4 / 8 / 2013$ & Serum & Neg & & & & & & & & \\
\hline & & Blood & Neg & Neg 7, 14 & Neg & & & & & & \\
\hline & unknown & FFPE bone marrow & Neg & N/A & N/A & & & & & & \\
\hline
\end{tabular}

N/A- Test not applicable for the sample tested

FFPE- Formalin-fixed paraffin-embedded

Bh- Bartonella henselae, genotypes SA2 or Fizz

(identity 527/527 bp) was independently amplified and sequenced from the mitral valve prosthesis removed February 13, 2013, just prior to his death. Based upon blood and tissue PCR amplification and DNA sequencing results, this veterinarian was infected with two $B$. henselae genotypes in January 2012 and the Fizz genotype persisted at the time of his death. When and how these infections were acquired, how long the infections persisted, and if $B$. henselae contributed to his illness, FUO and ultimately his death will never be known.

I have been a veterinary internist at North Carolina State University, College of Veterinary Medicine since 1982. As such, I consult with regional veterinarians on a near daily basis. Despite the fact that Veterinarian \#2 practiced medicine in North Carolina for 37 years, I did not know him personally; however, as fate would have it, he lived in a house along the North Carolina coast adjacent to a close friend who was familiar with our Bartonella research. Thus, it was a mutual friend who suggested Bartonella testing. Veterinarian \#2 developed lymphadenopathy involving the neck, axillary lymph node $(2 \mathrm{~cm})$, and root of the mesentery (radiographically a $4 \mathrm{~cm}$ lymph node). On February $24^{\text {th }}, 2012$, the left supraclavicular lymph node was surgically excised at Carolina East Medical Center. Histologically, the lymph node contained a mixed population of small and large lymphocytes, plasma cells, and scattered neutrophils, without evidence of necrosis, granulomatous inflammation, or abscess formation. There were no Reed-Sternberg cells indicative of Hodgkin's disease. Preliminary pathological diagnosis was lymphadenitis of uncertain etiology. Fungal, bacterial and mycobacterial cultures were negative. Immunophenotypic studies, performed at 
Johns Hopkins Hospital as part of the standard lymphoma protocol, supported a diagnosis of angioimmunoblastic $\mathrm{T}$ cell lymphoma (AILT), with no specific morphologic or immunophenotpic characteristics to allow subclassification. In situ hybridization for Epstein Barr Virus (EBER) identified scattered positive cells. An addendum report from The Johns Hopkins Hospital contained the following statement: "Careful correlation with history is recommended to rule out immunodeficiency. The morphologic features coupled with a high proliferation rate and numerous mitoses are not seen in typical AILT cases; however, additional studies and clinical correlation are needed to exclude this possibility." March $15^{\text {th }}, 2012$, the patient was referred to Duke University Medical Center where the pathologist concurred with the diagnosis of AILT, however, the attending lymphoma oncology specialist suggested the possibility of self-limiting lymphadenitis. July $17^{\text {th }}, 2012$, a pathologist at MD Anderson Medical Center concurred with the AILT diagnosis. A cervical lymph node, biopsied July $25^{\text {th }}$, had effacement of normal nodal architecture by atypical lymphoid infiltrates, accompanied by mild vascular endothelial proliferation, and scattered eosinophils and plasma cells. Angioimmunoblastic features were less prominent and features of lymphoma were more prominent than the previous biopsy. EBER staining was negative. Immuno-histochemical staining again supported a diagnosis of AILT. The cancer was PCR positive for clonal T-cell receptor gamma gene rearrangement and negative for clonal B-cell immunoglobulin gene rearrangement. ${ }^{1}$ Chemotherapy consisted of oral prednisone and five cycles of CHOP (cyclophosphamide, doxorubicin, vincristine, prednisone) therapy. Beginning five months after initiating $\mathrm{CHOP}$ chemotherapy, the patient began experiencing frequent rigors, night sweats, and was ultimately diagnosed with FUO, which at various time points was treated with intravenous and orally administered fluoroquinolones, cephalosporins, antivirals, antifungals, intravenous dexamethasone and oral prednisone, all of which failed to induce sustained resolution in the FUO. As described for Veterinarian \#1, infection with Bartonella henselae can cause FUO $[18,19]$.

By September 2012, Veterinarian \#2 was referred to MD Anderson Center. He was anemic (HB $8.2 \mathrm{mg} / \mathrm{dl}$, thrombocytopenic $[89,000$ platelets/ul]), and had a lymphocytosis $(12,500 / \mathrm{ul})$. A core bone marrow biopsy contained multiple, atypical, lymphohistiocytic aggregates, with a prominent epithelioid component. Immunophenotyping supported AILT with marrow involvement. In October 2012, Veterinarian \#2 requested Bartonella testing. Because of the historical administration of several antibiotics, BAPGM enrichment blood culture/PCR was likely to be diagnostically less sensitive; therefore, paraffinembedded lymph node biopsies obtained in February and July 2012 were tested by conventional PCR. Bartonella henselae (SA2 genotype) was successfully amplified and sequenced from the July lymph node specimen. Shortly thereafter, treatment with doxycycline as the sole therapy was instituted for bartonellosis and the rigors and fevers temporarily resolved. In completing the study questionnaire, this veterinarian reported being healthy prior to the development of lymphadenopathy in February 2012, and with the exception of FUO accompanied by rigors and night sweats, CHOP (cyclophosphamide, doxorubicin, vincristine, prednisone) chemotherapy had been well tolerated. When the $B$. henselae lymph node PCR result became available, I related our experience with doxycycline therapy in experimentally and naturally infected cats [21], and naturally-infected dogs [22] to the patient's infectious disease physicians. Doxycycline as a sole antibiotic would suppress Bartonella sp. bacteremia, but rarely, if ever, cured the infection. In humans, doxycycline treatments as long as 3 months in duration have resulted in symptomatic and hematological improvement, but sequential blood culture/PCR indicated $B$. henselae infections persisted $[13,23]$.

Due to the progressive nature of the AILT, a decision was made to treat the patient with allogeneic bone marrow stem cell transplantation; however, this therapy was repeatedly delayed between October 2012 and April 2013 due to recurrent bouts of FUO, which were temporally followed administration of chemotherapy. B. henselae infection was not detected by BAPGM enrichment blood culture/PCR [24] in April 2013 (Table 2), shortly before his death on April 21 ${ }^{\text {st }}, 2013$. The planned allogeneic bone marrow stem cell transplantation was never performed.

In asking the question: "Did B. henselae contribute to the deaths of these two veterinarians?"; we would first have to ask, does $B$. henselae cause FUO and endocarditis? The answer is yes. A second important question is: "What microbiological evidence supports $B$. henselae infection?" For Veterinarian \#1, B. henselae DNA was amplified and sequenced from three diagnostic specimens (bone marrow, blood and mitral valve prosthesis) collected at three different time points between January 2012 and February 2013. For Veterinarian \#2, B. henselae DNA was amplified and sequenced from a paraffin-embedded lymph node obtained surgically, four months prior to PCR testing in our laboratory. Subsequently, despite ongoing febrile illness, serology and BAPGM enrichment blood culture testing failed to identify $B$. henselae DNA or antibodies. As summarized in a recent review [25], our research laboratory has substantial experience with paraffin embedded tissue PCR [26, 27]. We have also previously described precautions in processing tissues to avoid DNA carryover [28]. Our laboratory protocols describe, and we routinely enforce, rigid work flow patterns to avoid carryover or DNA contamination with amplified products. Also, negative DNA extraction, PCR amplification, and BAPGM 
enrichment blood culture controls are used routinely to assess Bartonella spp. DNA contamination with every sample set processed within the laboratory. DNA carryover and amplicon contamination are considered an unlikely source for the microbiological findings in these two veterinarians. Although isolation is the microbiological "gold standard" for documenting a bacterial infection, PCR amplification of organism-specific DNA sequences is being used to document the presence of fastidious [29], stealth [1] or "unculturable" bacteria from patient samples [30]. PCR amplification of organism-specific DNA sequences does not confirm that the bacteria is viable or that the organism is responsible for the patient's symptoms or pathology. However, the molecular microbiological evidence supported $B$. henselae infection in both veterinarians.

Another important microbiological question; "Was there serological evidence to support exposure to B. henselae?" For reasons that remain unclear, a substantial (50-75 \%) subset of Bartonella spp. bacteremic patients do not have detectable IFA antibodies [9, 31]. With chronic, asymptomatic or minimally symptomatic Bartonella bacteremia, a seronegative status may be the norm, rather than the exception; thus, serology is not a diagnostically or epidemiologically sensitive modality. Often after weeks or months of prior antibiotic therapy, many veterinary workers are tested for Bartonella infection as an afterthought or as a "test of last resort." Using currently available diagnostic techniques, these bacteria are difficult to enrich, to isolate or to PCR amplify from tissues under optimal testing conditions. Long delays before obtaining or processing patient specimens, concurrent or recent antibiotic administration, and the number of blood or tissue samples tested influence the sensitivity of the BAPGM enrichment blood culture/PCR platform. [24, 32] For biopsy specimens, the tissue sample size, the duration of formalin fixation prior to paraffin embedding, and the severity and type of inflammatory response $[26,27]$ are important factors that determine diagnostic PCR sensitivity. Collectively, these factors influence whether a diagnosis is confirmed or the infection is missed in a given patient. Timelier collection of optimal specimens from these two veterinarians may have resulted in different and diagnostically more beneficial Bartonella microbiological findings, than we reported above.

Assuming the possibility that both veterinarians were infected with viable bacteria at the onset of illness and/ or when tested, the next question becomes: "Did the bacterium play a role in the initiation or progression of each patient's illness?" For Veterinarian \#1, the approximate two-year history of non-specific, waxing and waning symptoms is consistent with the questionnaire responses reported by other Bartonella bacteremic veterinary workers [9-14]. Establishing causation for non-specific symptoms that accompany infectious and non-infectious disease processes is difficult, particularly due to comorbidities. However, documenting persistent Bartonella sp. bacteremia in "non-immunocompromised" individuals is not impossible, as we have repeatedly demonstrated [9$14,23]$. Persistent occult blood stream infection may predispose patients to ongoing microvascular injury, bacterial localization within various tissues including the vascular endothelium and heart valves, and the development of non-specific symptoms. One could hypothesize that Veterinarian \#1 progressed from non-specific symptoms to culture-negative endocarditis, to FUO, to infection of the mitral valve prosthesis over a three-year timeframe. Currently, physicians are taught that $B$. henselae infection in immunocompetent people is synonymous with cat scratch disease (CSD), which is considered a self-limiting infection. Although CSD is most often self-limiting, this does not appear to be uniformly true [33]. Performing a sequential, long-term cohort study of CSD patients in the United States, as reported from Israel [33], might identify a subset of persistently $B$. henselae bacteremic patients with associated symptomatology and allow for the documentation of progression of rheumatologic [34] and/or neurologic disease [15].

A biologically more complex question is: "Did B. henselae infection predispose to the development of lymphoma?" Bartonella spp. can invade numerous host cells, within which the bacteria modify cellular functions by injecting peptides and potentially transporting bacterial DNA into the cell $[1,4,6,34]$. B. henselae contains bacteriophages [35] that might also facilitate DNA translocation events. Bartonella spp. appear to play causative or cofactor roles in the development of vasoproliferative tumors in animals [36] and immunocompetent as well as immunocompromised people [6]. Comparative studies of naturally-occurring lymphoma involving animals and humans are warranted to potentially generate evidence that supports comparative infectious disease causation [25]. Although not well studied in human patients, dogs experimentally-infected with Bartonella vinsonii subsp. berkhoffii became immunosuppressed [37]. Infectioninduced immune suppression, as suggested by the pathologist reviewing the original lymph node biopsy from Veterinarian \#2, has been suggested to occur in association with human bartonellosis, caused by $B$. bacilliformis $[1,4]$. Potentially, DNA translocation events in conjunction with persistent infection-induced immune suppression could predispose a patient to develop lymphoma.

Did $B$. henselae play a role in the deaths of two veterinarians? Perhaps yes and perhaps no. For both veterinarians, it seems likely that $B$. henselae was responsible for FUO. During their illnesses, and after their respective deaths, I communicated with both wives. Based upon their comments during these challenging conversations, it is their hope that some good may come from their 
husband's deaths. Both men were outstanding fathers, husbands, veterinarians and community servants, each participating in a large number of volunteer activities. From my perspective, it is time for a "Bartonella tipping point," whereby this emerging pathogen is accorded a higher national (United States) and international research priorities.

\section{Endnotes}

\section{${ }^{1}$ NeoGenomics Laboratories, Irvine, Ca.}

\section{Abbreviations}

FUO: Fever of unknown origin; EBER: Epstein Barr Virus; AlLT: Angioimmunoblastic T cell lymphoma; CSD: Cat Scratch Disease.

\section{Competing interests}

In conjunction with Dr. Sushama Sontakke and North Carolina State University, Dr. Breitschwerdt holds U.S. Patent No. 7,115,385; Media and Methods for cultivation of microorganisms, which was issued October 3, 2006. He is the chief scientific officer for Galaxy Diagnostics, a company that provides advanced diagnostic testing for the detection of Bartonella species and other vector borne pathogens in animals and humans.

\section{Authors' contributions}

EBB coordinated communications and generated the manuscript. Others are acknowledged for their respective contributions.

\section{Authors' information}

Dr. Breitschwerdt is a professor of medicine and director of the Intracellular Pathogens Research Laboratory, Center for Comparative Medicine and Translational Research, College of Veterinary Medicine, North Carolina State University, Raleigh, NC. His research interests include diagnosis, treatment and prevention of vector-borne intracellular pathogens.

\section{Acknowledgements}

The author thanks Bayer Health Care-Animal Health Division for kindly supporting the publication of this manuscript in the framework of the $10^{\text {th }}$ CVBD World Forum symposium. The author also thanks Jessica Wong for technical assistance, Julie Bradley and Barbara Hegarty for serological testing, Drs. Nandhakumar Balakrishnan, Ricardo Maggi and Patricia Mascarelli for performing BAPGM enrichment blood culture/PCR and tissue PCR testing, and Tonya Lee for editorial assistance. My deepest sympathy and thanks to the wives of these veterinarians for providing medical histories and other details included in this commentary.

\section{Received: 20 March 2015 Accepted: 27 May 2015}

\section{Published online: 12 June 2015}

\section{References}

1. Pulliainen AT, Dehio C. Persistence of Bartonella spp. stealth pathogens: from subclinical infections to vasoproliferative tumor formation. FEMS Microbiol Rev. 2012;36:563-99.

2. Chomel BB, Boulouis HJ, Maruyama S, Breitschwerdt EB. Bartonella spp. in pets and effect on human health. Emerg Infect Dis. 2006;12(3):389-94.

3. Florin TA, Zaoutis TE, Zaoutis LB. Beyond cat scratch disease: widening spectrum of Bartonella henselae infection. Pediatrics. 2008;121:e1413-25.

4. Ben-Tekaya H, Gorvel JP, Dehio C. Bartonella and Brucella-weapons and strategies for stealth attack. Cold Spring Harb Perspect Med. 2013;3(8): doi: 10.1101/cshperspect.a010231

5. Koehler JE, Sanchez MA, Garrido CS, Whitfeld MJ, Chen FM, Berger TG, et al. Molecular epidemiology of bartonella infections in patients with bacillary angiomatosis-peliosis. N Engl J Med. 1997;337:1876-83.

6. Kempf VA, Lebiedziejewski M, Alitalo K, Wälzlein JH, Ehehalt U, Fiebig J, et al Activation of hypoxia-inducible factor-1 in bacillary angiomatosis: evidence for a role of hypoxia-inducible factor-1 in bacterial infections. Circulation. 2005:111:1054-62.
7. Boulouis HJ, Chang CC, Henn JB, Kasten RW, Chomel BB. Factors associated with the rapid emergence of zoonotic Bartonella infections. Vet Res. 2005;36(3):383-410.

8. Breitschwerdt EB, Maggi RG, Chomel BB, Lappin MR. Bartonellosis: An emerging infectious disease of zoonotic importance to animals and human beings. J Vet Emerg Crit Care. 2010;20:8-30.

9. Maggi RG, Mascarelli PE, Pultorak EL, Hegarty BC, Bradley JM, Mozayeni BR, et al. Bartonella spp. bacteremia in high-risk immunocompetent patients. Diagn Microbiol Infect Dis. 2011;71:430-7.

10. Lantos PM, Maggi RG, Ferguson B, Varkey J, Park LP, Breitschwerdt EB, et al. Detection of Bartonella species in the blood of veterinarians and veterinary technicians: A newly recognized occupational hazard. Vector Borne Zoonotic Dis. 2014;14(8):563-70.

11. Breitschwerdt EB, Maggi RG, Duncan AW, Nicholson WL, Hegarty BC, Woods CW. Bartonella species in blood of immunocompetent persons with animal and arthropod contact. Emerg Infect Dis. 2007;13:938-41.

12. Breitschwerdt EB, Maggi RG, Nicholson WL, Cherry NA, Woods CW. Bartonella spp. bacteremia in patients with neurological and neuro-cognitive dysfunction. J Clin Microbiol. 2008:46(9):2856-61.

13. Breitschwerdt EB, Maggi RG, Lantos PM, Woods CW, Hegarty BC, Bradley JM. Bartonella vinsonii subsp. berkhoffii and Bartonella henselae in a father and daughter with neurological disease. Parasit Vectors. 2010;3:29.

14. Oliveira AM, Maggi RG, Woods CW, Breitschwerdt EB. Putative needle stick transmission of Bartonella vinsonii subsp. berkhoffii to a veterinarian. J Vet Intern Med. 2010;24:1229-32.

15. Breitschwerdt EB, Sontakke S, Hopkins S. Neurological manifestations of Bartonellosis in immunocompetent patients: A composite of reports from 2005-2012. J Neuroparasitol. 2012;3:15.

16. Breitschwerdt EB. Bartonellosis: one health perspectives for an emerging infectious disease. ILAR J. 2014:55:46-58.

17. Chomel BB, Kasten RW, Williams C, Wey AC, Henn JB, Maggi R, et al. Bartonella endocarditis: a pathology shared by animal reservoirs and patients. Ann N Y Acad Sci. 2009;1166:120-6.

18. Lamas Cda C, Ramos RG, Lopes GQ, Santos MS, Golebiovski WF, Weksler C, et al. Bartonella and Coxiella infective endocarditis in Brazil: molecular evidence from excised valves from a cardiac surgery referral center in Rio de Janeiro, Brazil, 1998 to 2009. Int J Infect Dis. 2013;17:e65-6.

19. Tsukahara M, Tsuneoka H, Lino H, Murano I, Takahashi H, Uchida M. Bartonella henselae infection as a cause of fever of unknown origin. J Clin Microbiol. 2000;38:1990-1.

20. Guiyedi V, Haddad H, Okome-Nkoumou M, Gire F, Ongali B, Lore P, et al. Cat-scratch disease in adult hospitalized for prolonged-Fever associated with multiple lymphadenopathies and weight loss. Open Microbiol J. 2013;7:152-5.

21. Kordick DL, Papich MG, Breitschwerdt EB. Efficacy of enrofloxacin or doxycycline for treatment of Bartonella henselae or Bartonella clarridgeiae infection in cats. Antimicrob Agents and Chemoth. 1997;41:2448-55.

22. Pérez C, Maggi RG, Diniz PP, Breitschwerdt EB. Molecular and serological diagnosis of Bartonella infection in 61 dogs from the United States. J Vet Intern Med. 2011;25:805-10.

23. Sykes JE, Lindsay LL, Maggi RG, Breitschwerdt EB. Human coinfection with Bartonella henselae and two hemotropic mycoplasma variants resembling Mycoplasma ovis. J Clin Microbiol. 2010;48:3782-5.

24. Pultorak EL, Maggi RG, Mascarelli PE, Breitschwerdt EB. Serial testing from a three-day collection period using the BAPGM platform may enhance the sensitivity of Bartonella spp. detection in bacteremic human patients. J Clin Microbiol. 2013:57:1673-7.

25. Breitschwerdt EB, Linder KL, Day MJ, Maggi RG, Chomel BB, Kempf VAJ. Koch's Postulates and the pathogenesis of comparative infectious disease causation associated with Bartonella species. J Comp Pathol. 2013;1:1-11.

26. VanderHeyden TR, Yong SL, Breitschwerdt EB, Maggi RG, Mihalik AR, Parada JP, et al. Granulomatous hepatitis due to Bartonella henselae infection in an immunocompetent patient. BMC Infect Dis. 2012;23:17.

27. Balakrishnan N, Jawanda JS, Miller MB, Breitschwerdt EB. Bartonella henselae infection in a man with hypergammaglobulinaemia, splenomegaly and polyclonal plasmacytosis. J Med Microbiol. 2013;62:338-41.

28. Varanat M, Maggi RG, Linder KE, Horton S, Breitschwerdt EB. Cross-contamination in the molecular detection of Bartonella from paraffin-embedded tissues. Vet Pathol. 2009:46:940-4

29. Fredericks DN, Relman DA. Sequence-based identification of microbial pathogens: a reconsideration of Koch's postulates. Clin Microbiol Rev. 1996:9:18-33. 
30. Levy PY, Fournier PE, Fenollar F, Raoult D. Systematic PCR detection in culture-negative osteoarticular infections. Am J Med. 2013;126:1143.e25-33.

31. Maggi RG, Mozayeni BR, Pultorak EL, Hegarty BC, Bradley JM, Correa M, et al. Bartonella spp. bacteremia and rheumatic symptoms in patients from Lyme Disease-endemic region. Emerg Infect Dis. 2012;18:783-91.

32. Maggi $R G$, Mascarelli PE, Havenga $L N$, NAidoo V, Breitschwerdt EB. Co-infection with Anaplasma platys, Bartonella henselae and Candidatus Mycoplasma hematoparvum in a veterinarian. Parasit Vectors. 2013:6:106

33. Giladi M, Maman E, Paran D, Bickels J, Comaneshter D, Avidor B, et al. Cat-scratch disease-associated arthropathy. Arthritis Rheum. 2005;52:3611-7.

34. Siamer S, Dehio C. New insights into the role of Bartonella effector proteins in pathogenesis. Curr Opin Microbiol. 2014;23C:80-5.

35. Maggi RG, Breitschwerdt EB. Isolation of bacteriophages from Bartonella vinsonii subsp. berkhoffii and the characterization of Pap31 gene sequences from bacterial and phage DNA. J Mol Microbiol Biotechnol. 2005:9:44-51.

36. Beerlage C, Varanat M, Linder K, Maggi RG, Colley J, Kempf AJK, et al. Bartonella vinsonii subsp. berkhofffii and Bartonella henselae as potential causes of proliferative vascular disease in animals. Med Microbiol Immunol. 2012:201:319-26.

37. Pappalardo BL, Brown TT, Tompkins M, Breitschwerdt EB. Immunopathology of Bartonella vinsonii (berkhoffii) in experimentally infected dogs. Vet Immunol Immunopathol. 2001:83:125-47.

\section{Submit your next manuscript to BioMed Central and take full advantage of:}

- Convenient online submission

- Thorough peer review

- No space constraints or color figure charges

- Immediate publication on acceptance

- Inclusion in PubMed, CAS, Scopus and Google Scholar

- Research which is freely available for redistribution 